Supplement of The Cryosphere, 15, 1173-1186, 2021

https://doi.org/10.5194/tc-15-1173-2021-supplement

(C) Author(s) 2021. This work is distributed under

the Creative Commons Attribution 4.0 License.

(c) (1)

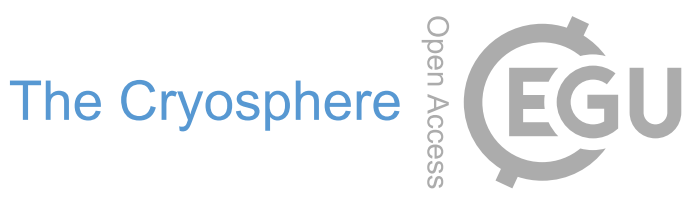

Supplement of

\title{
Physical properties of shallow ice cores from Antarctic and sub-Antarctic islands
}

Elizabeth Ruth Thomas et al.

Correspondence to: Elizabeth Ruth Thomas (lith@bas.ac.uk)

The copyright of individual parts of the supplement might differ from the CC BY 4.0 License. 

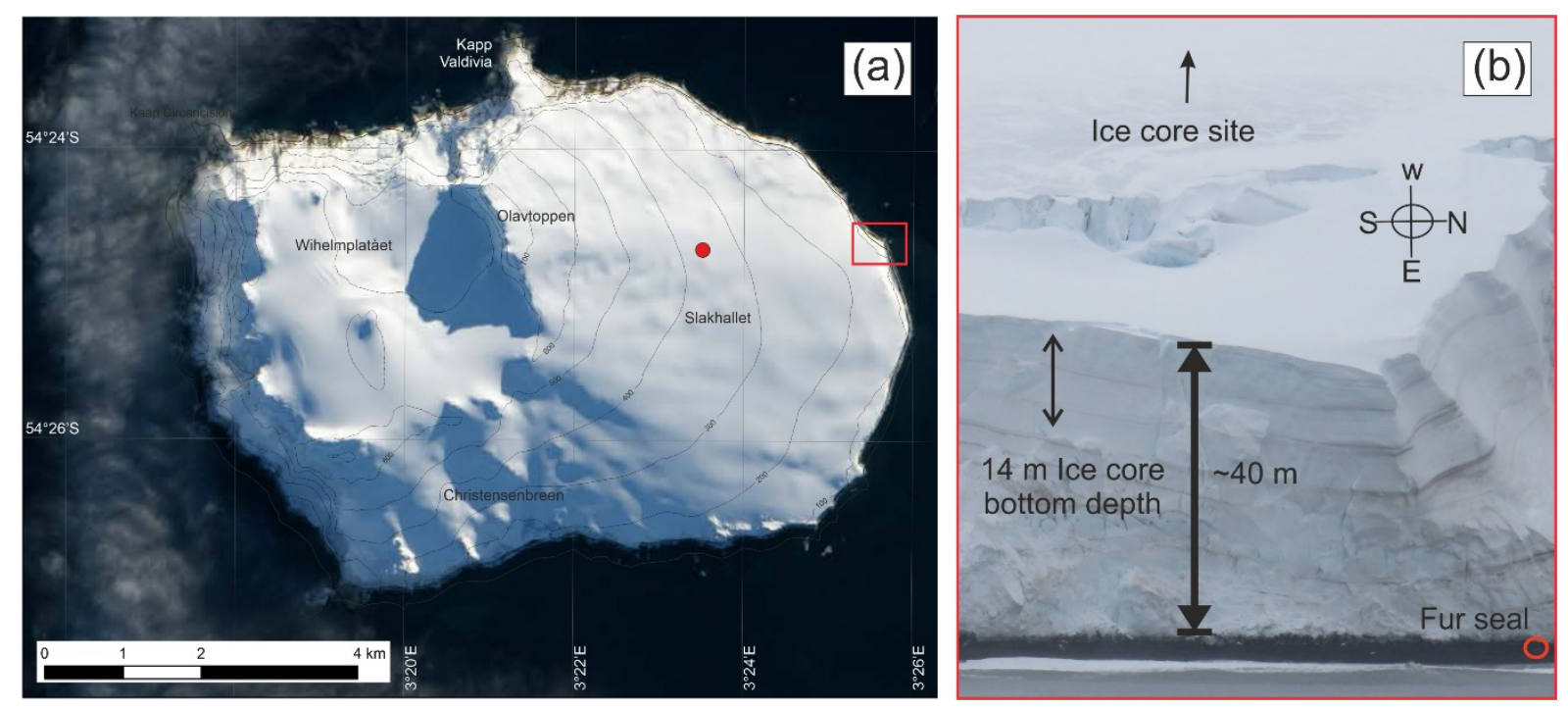

Figure S1: Visible layers on Bouvet Island. (a) Map of Bouvet island, showing the ice core drilling location (red dot) and the area the photo was taken (red box). Image credit Google Earth. (b) Photograph of an ice cliff taken from the ship, revealing the visible "dirty" layers that are assumed to represent dust or ash deposits (image credit E.R. Thomas). The depth estimates relative to the fir seals on the beach (red circle). 